\title{
Agrochemical properties of degraded desert sandy soils of Uzbekistan
}

\author{
Muradjon Karimov ${ }^{1}$, Normamat Namozov $^{1, *}$, and Bekzod Teshaboev ${ }^{1}$ \\ ${ }^{1}$ Tashkent State Agrarian University, University str., 2, Tashkent province, Uzbekistan, 100140
}

\begin{abstract}
This article presents the results of research conducted in desert sandy soils. The study found that the humus content in the soil was moderate in the upper layer, very low and low in the nitrate form of nitrogen, the amount of mobile phosphorus was low in the surface layer of the soil, and very low in the $1 \mathrm{~m}$ layer, high and very high in exchangeable potassium.
\end{abstract}

\section{Introduction}

Today, $25 \%$ of the world's land is degraded, covering 3.6 billion hectares of land and directly affecting the livelihoods of 1.0 billion people. [1] The main part of degraded lands falls on desert pastures. One of the urgent problems is to develop scientifically based measures to increase the efficiency of desert pasture use, protection of soil cover from degradation processes and their prevention [2].

Several studies are nowadays being conducted in the world to improve the ecological condition of pastures with degraded and low-yielding sandy desert soils and to plant food crops in priority areas [1-3]: identification of changes in soil cover as a result of degradation in sandy desert soils; overcoming the negative impact of desert pastures on soils by studying the phytoindicators of degradation; development of technologies to reduce the process of degradation in sandy desert soils by planting promising varieties of desert forage plants, taking into account the properties of sandy desert soils.

The main reasons for the decline in pasture productivity are [4-6]: first, climate change; secondly, in the context of the growing number of livestock at the disposal of the population and the process of pasture use is not regulated; third, the lack of a system of animal husbandry in the new conditions; fourth, the reduction of forage plant species in pastures and their replacement by other plant species of non-economic importance; fifthly, it can be explained by insufficient attention paid to irrigation, reclamation works in pastures and application of mineral fertilizers and organization of seed production. It is reasonable to acknowledge that all of these are factors that lead to pasture degradation and seriously impede the rapid development of the sector $[6,7]$.

Fertile soils should be able to provide crops with nutrients, water, air and heat $[6,10]$. Turning of sands into mud reduces the physical properties of the soil, water regime and the loss of nitrogen, phosphorus, potassium in the soil, as well as affects the growth and

\footnotetext{
*Corresponding author: nnamozov@mail.ru
} 
productivity of plants [2]. Researchers have studied the properties and flora of sandy desert soils $[2,4,5,9]$. Given that the preservation and increase of productivity of pastures is a topical issue today, their condition plays an important role in ensuring the stability of life in rural areas, the application of all factors in this work will further enhance the economic power of the country and the welfare of the population [10]. One of the most important issues to be addressed is the efficient use of pasture resources, the use of advanced technologies and effective methods to improve reclamation and address environmental issues. In fodder crops, the highest seed yield was observed in oats. Its yield was $26.5 \pm$ $0.69 \mathrm{q} / \mathrm{ha}$, and it was found that it harvested $6.0 \mathrm{q} /$ ha more seeds than millet [10].

In addition to the fact that one of the desert and semi-desert plants has a wide area, the division of it as a polymorphic plant into rocky, sandy, loamy soil ecological types also allows it to be cultivated in a variety of soil-climatic conditions [8].

\section{Materials and methods}

Farms specializing in desert livestock have almost no use of natural pastures. The pastures belonging to them are artificially planted male pastures, male grass + esparto and izen pastures. Typically, male grasslands are used in the spring, male grass + esparto pastures in the summer, and izen pastures in the fall and winter [10]. Therefore, the sustainability of pasture feed yields fully ensures the efficiency of American pastoralism regardless of the coming year [7].

Since the bulk of the livestock is in the population, $44 \%$ of the pastures are now overgrazed, firstly because the annual and perennial plants, shrubs and shrubs that strengthen the soil layers are on the verge of extinction, and secondly because ungulates are destroying the soil structure. Lastly, that medicinal grasses growing in pastures are declining.

When studying the amount of mineral nutrients in the soil sections, it was observed that mineral nutrients are abundant in the upper layers of the soil, and their content decreases as they fall into the lower layers. The fact that the amount of nitrogen in the form of nitrate $\left(\mathrm{NO}_{3}\right)$ in the $0-13 \mathrm{~cm}$ layers of the soil is $6.9-24.6 \mathrm{mg} / \mathrm{kg}$ indicates that these substances have a high dynamics. The presence of a mobile form of phosphorus nutrient found that the amount of $\mathrm{R}_{2} \mathrm{O}_{5}$ was more abundant in the $0-13 \mathrm{~cm}$ section of soil sections than in the upper layer in the lower $13-33 \mathrm{~cm} 4.7-9.6 \mathrm{mg} / \mathrm{kg}$ layers of $19.5-24.2 \mathrm{mg} / \mathrm{kg}$.

\section{Results and discussion}

According to the analysis of the data obtained from the study, the total amount of humus is $0-13 \mathrm{~cm} 0.73-1.37 \%$. Despite the abundance of plant remains, $33-71 \mathrm{~cm}$ in the lower layers of the soil is poorly supplied with $0.19-0.27 \%$ humus. This indicates that the activity of microorganisms in these soils is high, i.e., the warm weather and sufficient humidity in the spring and autumn months lead to complete mineralization of organic matter (Table 1). 
Table 1. Agrochemical characteristics of experimental soils (2019)

\begin{tabular}{|c|c|c|c|c|c|c|c|c|c|}
\hline \multirow{2}{*}{ 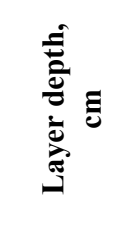 } & \multirow{2}{*}{ 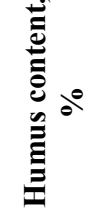 } & \multicolumn{3}{|c|}{ Total, \% } & \multirow{2}{*}{$\overbrace{z}^{\infty}$} & \multicolumn{2}{|c|}{ Reactive, mg/kg } & \multirow{2}{*}{ లే } & \multirow{2}{*}{$\begin{array}{l}0 \\
0 \\
0 \\
0\end{array}$} \\
\hline & & $\mathbf{N}$ & $\mathbf{P}$ & $\mathbf{K}$ & & $\mathrm{P}_{2} \mathrm{O}_{5}$ & $\mathbf{K}_{2} \mathbf{O}$ & & \\
\hline \multicolumn{10}{|c|}{ 12-soil layer } \\
\hline $0-12$ & 1.139 & 0.078 & 0.069 & 0.64 & 8.7 & 30.0 & 240.8 & 6.82 & 0.077 \\
\hline $12-33$ & 0.422 & 0.034 & 0.062 & 0.86 & 3.4 & 9.6 & 192.6 & 7.7 & 0.066 \\
\hline $33-65$ & 0.274 & 0.021 & 0.056 & 0.98 & 3.1 & 5.0 & 180.6 & 7.7 & 0.077 \\
\hline $65-110$ & - & - & - & - & 2.9 & - & - & - & - \\
\hline \multicolumn{10}{|c|}{ 13-soil layer } \\
\hline $0-10$ & 0.971 & 0.067 & 0.084 & 0.99 & 11.1 & 32.0 & 394.9 & 6.38 & 0.066 \\
\hline $10-35$ & 0.422 & 0.028 & 0.078 & 0.77 & 4.9 & 18.0 & 322.7 & 6.27 & 0.071 \\
\hline $35-67$ & 0.401 & 0.025 & 0.069 & 0.92 & 3.2 & 8.4 & 252.8 & 6.6 & 0.077 \\
\hline $67-105$ & & & & & 2.9 & 4.7 & 204.7 & 7.37 & 0.088 \\
\hline \multicolumn{10}{|c|}{ 14-soil layer } \\
\hline $0-8$ & 1.329 & 0.087 & 0.088 & 1.06 & 12.5 & 33.0 & 293.8 & 6.38 & 0.066 \\
\hline $8-24$ & 0.422 & 0.031 & 0.075 & 1.01 & 3.5 & 6.8 & 216.7 & 7.48 & 0.099 \\
\hline $24-49$ & 0.338 & 0.027 & 0.066 & 0.86 & 2.3 & 4.4 & 192.6 & 8.36 & 0.082 \\
\hline $49-86$ & & & & & 1.8 & & & 7.81 & 0.104 \\
\hline \multicolumn{10}{|c|}{ 15-soil layer } \\
\hline $0-7$ & 0.823 & 0.061 & 0.084 & 0.78 & 10.2 & 29.0 & 293.8 & 6.93 & 0.077 \\
\hline $7-22$ & 0.401 & 0.028 & 0.780 & 0.76 & 6.2 & 16.5 & 252.8 & 704 & 0.066 \\
\hline $22-45$ & 0.317 & 0.024 & 0.072 & 0.94 & 4.4 & 6.4 & 216.7 & 7.15 & 0.066 \\
\hline $45-86$ & & & & & 3.2 & & & 7.7 & 0.072 \\
\hline \multicolumn{10}{|c|}{ 16-soil layer } \\
\hline $0-7$ & 0.823 & 0.057 & 0.084 & 1.08 & 14.9 & 21.4 & 293.8 & 7.04 & 0.093 \\
\hline $7-27$ & 0.443 & 0.033 & 0.078 & 0.99 & 6.2 & 7.6 & 240.8 & 8.36 & 0.143 \\
\hline
\end{tabular}




\begin{tabular}{|c|c|c|c|c|c|c|c|c|c|}
\hline $27-49$ & 0.401 & 0.027 & 0.075 & 0.85 & 4.9 & 3.8 & 228.8 & 8.58 & 0.137 \\
\hline $49-86$ & & & & & 3.0 & & & 8.03 & 0.148 \\
\hline
\end{tabular}

In February, at a depth of $0-9 \mathrm{~cm}$ in the 5th section, the total nitrogen was $0.062 \%$, phosphorus $0.108 \%$ and potassium $0.36 \%$, humus $0.904 \%$, carbonates $5.94 \%$ and gypsum $0.077 \%$, reached at a depth of $9-22 \mathrm{~cm}$, the total nitrogen was $0.021 \%$, phosphorus $0.088 \%$ and potassium $0.33 \%$, humus $0.231 \%$, carbonates $6.05 \%$ and gypsum $0.088 \%$. At a depth of $22-41 \mathrm{~cm}$, the total nitrogen was $0.026 \%$, phosphorus $0.092 \%$ and potassium $0.36 \%$, humus $0.337 \%$, carbonates $6.38 \%$ and gypsum $0.088 \%$.

According to the results of agrochemical analysis of samples taken between the third decade of April, the amount of humus in the total area at an average layer depth of $0-9 \mathrm{~cm}$ was $0.612-0.844 \%$, which is close to the results obtained in September 2012, ie an average of $0.739-1.372 \%$ reached The results of the analysis of the total amount of nutrients were as follows, ie in April 2013, the content of nitrogen, phosphorus and potassium in the layer depth of $0-8 \mathrm{~cm}$ averaged $0.041-0.125 \%, 0.092-0.108 \%, 0.39-0.57 \%$, respectively. did. According to the agrochemical analysis performed in September 2012 on the same indicators, the average amounts of total nitrogen, phosphorus and potassium were 0.050 $0.097 \%, 0.096-0.116 \%$ and $0.44-0.63 \%$, respectively.

The following results were obtained from the analysis of the amounts of mobile forms of nutrients $\mathrm{NO}_{3}, \mathrm{R}_{2} \mathrm{O}_{5}, \mathrm{~K}_{2} \mathrm{O}$. The amount of nitrogen in the form of nitrate was 6.2-7.8 $\mathrm{mg} / \mathrm{kg}$ at a layer depth of $0-8 \mathrm{~cm}$. The amounts of mobile phosphorus $\left(\mathrm{R}_{2} \mathrm{O}_{5}\right)$ and exchangeable potassium $\left(\mathrm{K}_{2} \mathrm{O}\right)$ were as follows: $7.6-12.4 \mathrm{mg} / \mathrm{kg}$ and $216.7-366.0 \mathrm{mg} / \mathrm{kg}$. These nutrients were $19.5-24.2 \mathrm{mg} / \mathrm{kg}$ and $279.3-394.9 \mathrm{mg} / \mathrm{kg}$ in the same layers in the fall of 2012, respectively.

According to the analysis of the obtained data, in 2014, at a depth of 0-12 cm layer of the 12 th section, the total nitrogen was $0.078 \%$, phosphorus $0.069 \%$ and potassium $0.64 \%$, humus content in this layer was $1.139 \%$, carbonate content was $6.82 \%$, gypsum the amount was $0.077 \%$. At a depth of $12-33 \mathrm{~cm}$, the total nitrogen was $0.034 \%$, phosphorus $0.062 \%$ and potassium $0.86 \%$, humus $0.422 \%$, carbonates $7.7 \%$ and gypsum $0.066 \%$. At a depth of $33-65 \mathrm{~cm}$, the total nitrogen was $0.021 \%$, phosphorus $0.056 \%$ and potassium $0.98 \%$, humus $0.274 \%$, carbonates $7.7 \%$ and gypsum $0.077 \%$ (Table 1 ).

At a depth of $0-10 \mathrm{~cm}$ in section 13, gross nitrogen was $0.067 \%$, phosphorus $0.084 \%$ and potassium $0.99 \%$, humus $0.971 \%$, carbonates $6.38 \%$ and gypsum $0.066 \%$. At a depth of $10-35 \mathrm{~cm}$, the total nitrogen was $0.028 \%$, phosphorus $0.078 \%$ and potassium $0.77 \%$, humus $0.422 \%$, carbonates $6.27 \%$ and gypsum $0.071 \%$. At a depth of $35-67 \mathrm{~cm}$, the total nitrogen was $0.025 \%$, phosphorus $0.069 \%$ and potassium $0.92 \%$, humus $0.401 \%$, carbonates $6.6 \%$ and gypsum $0.077 \%$.

At a depth of 0-7 cm layer of section 16, the total nitrogen was $0.057 \%$, phosphorus $0.084 \%$ and potassium content $1.08 \%$, humus content in this layer was $0.823 \%$, carbonate content was $7.04 \%$ and gypsum content was $0.093 \%$. At a depth of $7-27 \mathrm{~cm}$, the total nitrogen was $0.033 \%$, phosphorus $0.078 \%$ and potassium $0.99 \%$, humus $0.443 \%$, carbonates $8.36 \%$ and gypsum $0.143 \%$. At a depth of $27-49 \mathrm{~cm}$, the total nitrogen was $0.027 \%$, phosphorus $0.075 \%$ and potassium $0.85 \%$, humus $0.401 \%$, carbonates $8.58 \%$ and gypsum $0.137 \%$.

\section{Conclusion}

Based on the results of the analysis of soil sections, the following conclusions were drawn. During this research, it was found to be that the amount of humus in the soil is 
average in the upper layer with humus, very low and low in nitrate form of nitrogen, the amount of mobile phosphorus is low in the surface layer of the soil, and in the layer up to 1 $\mathrm{m}$ belongs to the group of high and very high exchangeable potassium.

\section{References}

1. N. Teshaev, B. Mamadaliyev, A. Ibragimov, S. Khasanov, IOP Publishing 883(1), 012080 (2020)

2. A. Jumanov, S. Khasanov, A. Tabayev, G. Goziev, U. Uzbekov, E. Malikov, IOP Publishing 614(1), 012150 (2020)

3. I. Aslanov, S. Khasanov, Y. Khudaybergenov, M. Groll, Ch. Opp, F. Li, E. Ramirez Del-Valle, E3S Web of Conferences 227, 02005 (2021)

4. R. A. Kulmatov, S. A. Adilov, S. Khasanov, IOP Publishing 614(1), 012149 (2020)

5. Methods of chemical analysis of soil used in the laboratory of mass analysis, 148 (TSAU Press, Tashkent, 2002)

6. N. Namozov, D. Kodirova, M. Usmonova, International Journal of Scientific and Technology Research 9(3), 5491-5493 (2020)

7. L. A. Gafurova, D. A. Kodirova, G. T. Djalilova, O. K. Ergasheva, Journal of Critical Reviews 7(2), 2020 (2019)

8. G. L. Akramovna, K. D. Abdukarimovna, European science review, 5-6 (2018)

9. Z. Jabbarov, T. Abdrakhmanov, S. Akhmedov, U. Nomozov, M. Abdurahmonova, Bulletin of National University of Uzbekistan: Mathematics and Natural Sciences 3(1), 74-85 (2020)

10. R. Harrison, B. Waldron, K. Yensen, T. Monako, A. Palasso, Rangelands 24(5), 3-7 (2002) 